\title{
A Comparative Analysis of Ropivacaine- Fentanyl vs Bupivacaine- Fentanyl in Labour Analgesia
}

\author{
Vikas Aron ${ }^{1}$, Kapil Lamba ${ }^{2}$ \\ ${ }^{1}$ Assistant Professor, Rajshree Medical College \& Research Institute Bareilly, ${ }^{2}$ Professor \& HOD, Department of Anesthesia, Rajshree Medical Research \\ Institute \& Hospital, Bareilly.
}

\section{Abstract}

Background: The pains of labor result in a maternal stress response, which is neither beneficial for the fetus nor the mother. The present study was conducted to compare ropivacaine- fentanyl vs Bupivacaine-Fentanyl in labour analgesia. Subjects and Methods: The present study was conducted on 48 females of ASA Grades I and II, who requested epidural labour analgesia. Patients were divided into two equal groups. Group I patients received $10 \mathrm{~mL}$ of bupivacaine $0.1 \%$ + fentanyl $20 \mu \mathrm{g}$ and group II patients received $10 \mathrm{~mL}$ of ropivacaine $0.1 \%+$ fentanyl $20 \mu \mathrm{g}$. Fetal heart rate, blood pressure was monitored regularly. VAS scale was also assessed. Results: There was non- significant difference in MAP, MHR and FHR in group I and II at baseline and lowest value (P>0.05). Onset on analgesia in group I was 9.5 minutes and in group II was 19.2 minutes. Duration of analgesia in group I was 74.1 minutes and in group II was 64.5 minutes. The difference was significant $(\mathrm{P}<0.05)$. Conclusion: Combinations of ropivacaine or bupivacaine with fentanyl achieve equally effective and excellent labour analgesia.

Keywords: Bupivacaine, Ropivacaine, Heart rate.

Corresponding Author: Dr. Vikas Aron, Assistant Professor, Rajshree Medical College \& Reserch Institute Bareilly.

Received: October 2019

Accepted: November 2019

\section{Introduction}

The pains of labor result in a maternal stress response, which is neither beneficial for the fetus nor the mother. Evidence is suggestive that labor disorders including maternal hypertension, dystocia, meconium staining, and fetal distress are stress related. Hence, maternal pain relief not only benefits the parturient, but her neonate also. Maternal and fetal effects of analgesia during labor remain central to discussions among patients, anesthesiologists, and an obstetrical caregivers with the controversies in obstetrical anesthesia including the effects of regional anesthesia on the progress and outcome of labor as well as effects on the neonate.

Of all the available methods of labor analgesia, epidural analgesia satisfies the basic requirements of labor analgesia by fulfilling the objective of decreasing the pains of labor without affecting other sensations such as a desire to push and to allow normal walking while preserving the tone of pelvic floor muscles as well as retaining the sensation of the baby's head in the vagina; thus, allowing labor to proceed unhindered.

Ropivacaine is an alternative and is an amide type local anaesthetic, structurally similar to bupivacaine and mepivacaine. In early animal and human studies, ropivacaine (6-propyl pipecoloxylidide hydrochloride) demonstrated local anaesthetic properties with a potency and duration of action slightly lesser than that of bupivacaine. In addition, the depth and duration of motor block were less with ropivacaine. Low doses of local anaesthetic or opioid combinations are administered to provide a continuous T10L1 sensory block, during the first stage of labour. Further supplementation may be required, during the late first stage and second stage, to achieve a sacral block. The present study was conducted to compare ropivacaine- fentanyl vs Bupivacaine-Fentanyl in labour analgesia.

\section{Subjects and Methods}

The present study was conducted in the department of Obstetrics \& Gynaecology. It comprised of 48 females of ASA Grades I and II, who requested epidural labour analgesia. Ethical committee approval of the hospital and written informed consent was taken from patients.

Data such as name, age etc. was recorded. Patients were divided into two equal groups. Group I patients received $10 \mathrm{~mL}$ of bupivacaine $0.1 \%+$ fentanyl $20 \mu \mathrm{g}$ and group II patients received $10 \mathrm{~mL}$ of ropivacaine $0.1 \%+$ fentanyl $20 \mu \mathrm{g}$. Fetal heart rate, blood pressure was monitored regularly. VAS scale was also assessed. Results were tabulated and subjected to statistical analysis. The p-value $<0.05$ was considered significant.

\section{Results}

[Table 1] shows that Group I patients received $10 \mathrm{~mL}$ of bupivacaine $0.1 \%+$ fentanyl $20 \mu \mathrm{g}$ and group II patients received $10 \mathrm{~mL}$ of ropivacaine $0.1 \%+$ fentanyl $20 \mu \mathrm{g}$. Each 
group had 24 patients.

Table 1: Distribution of patients
\begin{tabular}{|l|l|l|}
\hline Groups & Group I & Group II \\
\hline Agent & $\begin{array}{l}\text { bupivacaine } 0.1 \%+ \\
\text { fentanyl } 20 \mu \mathrm{g}\end{array}$ & $\begin{array}{l}\text { ropivacaine } 0.1 \%+\text { fentanyl } \\
20 \mu \mathrm{g}\end{array}$ \\
\hline Number & 24 & 24 \\
\hline
\end{tabular}

Table 2: Hemodynamic data in both groups

\begin{tabular}{|l|l|l|l|}
\hline Groups & Group I & Group II & \multirow{2}{*}{ P value } \\
\hline MAP (baseline) & 123.4 & 126.8 & \\
\hline MAP (lowest) & 100 & 100 & \\
\hline MHR (baseline) & 94.8 & 92.6 & \\
MHR (lowest) & 76.5 & 72.1 & \\
\cline { 1 - 3 } FHR (baseline) & 140.6 & 142.7 & \\
\cline { 1 - 3 } FHR (baseline) & 130.6 & 134.2 & \\
\hline
\end{tabular}

[Table 2, Figure 1] shows that there was non- significant difference in MAP, MHR and FHR in group I and II at baseline and lowest value $(\mathrm{P}>0.05)$.

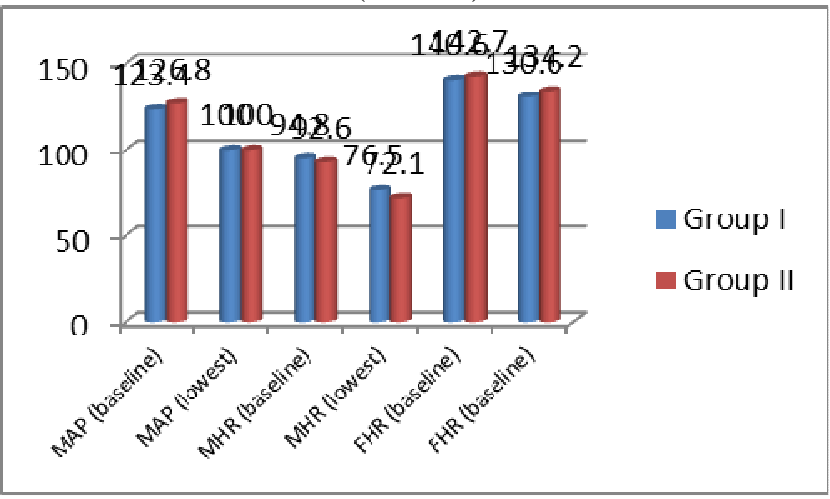

Figure 1: Hemodynamic data in both groups

Table 3: Onset and duration of analgesia
\begin{tabular}{|l|l|l|l|}
\hline Groups & Group I & Group II & P value \\
\hline Onset of analgesia (mins) & 9.5 & 19.2 & 0.01 \\
\hline Duration of analgesia (mins) & 74.1 & 64.5 & 0.02 \\
\hline
\end{tabular}

[Table 3, Figure 2] shows that onset on analgesia in group I was 9.5 minutes and in group II was 19.2 minutes. Duration of analgesia in group I was 74.1 minutes and in group II was 64.5 minutes. The difference was significant $(\mathrm{P}<0.05)$.

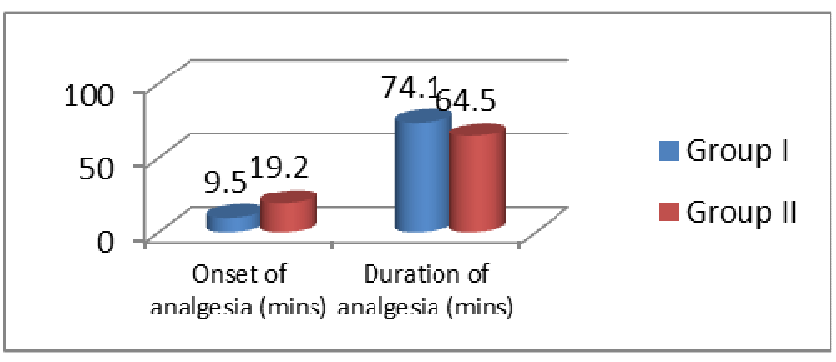

Figure 2: Onset and duration of analgesia

\section{Discussion}

Ropivacaine, an amide local anesthetic is less cardiotoxic in animals as well as it may also be more selective for sensory fibers when compared to other local anesthetics, producing less motor block. This allows for increased maternal ambulation and also allows for normal progression of labor, which translates into fewer instrumental deliveries and more vaginal deliveries although this is controversial. ${ }^{[5]}$ These factors suggest that ropivacaine may be superior to bupivacaine in obstetric analgesia. Minimum local anesthetic concentration (MLAC) studies by up and down sequential allocation have found both $0.2 \%$ and $0.1 \%$ ropivacaine to be effective for labor analgesia. ${ }^{[6]}$ The drugs to be used for this purpose should be quick in onset and long acting with minimum motor blockade and have no significant adverse effects on the mother and fetus. The duration of analgesia may be increased by intermittent top-ups. Commonly used drugs include lidocaine, bupivacaine, ropivacaine, morphine, chloroprocaine, tramadol, fentanyl, and sufentanil. ${ }^{[7]}$ The present study was conducted to compare ropivacainefentanyl vs Bupivacaine-Fentanyl in labour analgesia.

In present study, group I patients received $10 \mathrm{~mL}$ of bupivacaine $0.1 \%+$ fentanyl $20 \mu \mathrm{g}$ and group II patients received $10 \mathrm{~mL}$ of ropivacaine $0.1 \%+$ fentanyl $20 \mu \mathrm{g}$. Each group had 24 patients. Chetty et al, ${ }^{[8]}$ found that effective labor analgesia with no motor blockade was observed in both groups with no failure rate. Onset of analgesia was significantly faster in group R2 (75\% parturients in 0-5 min) as compared to group R1 (25\% parturients in $0-5 \mathrm{~min}), \mathrm{P}<$ 0.001 . Duration of analgesia after initial bolus dose was also significantly longer in group R2 $(132 \pm 56.81 \mathrm{~min})$ than in group R1 (72.25 \pm 40.26 min), $\mathrm{P}<0.001$. Mean VAS scores were significantly less in group R2 than in group R1 at 5, 60, and $90 \mathrm{~min}, \mathrm{P}<0.01$. Requirement of top-up doses was significantly less in group R2 $(0.05 \pm 0.22)$ as compared to group $\mathrm{R} 1 \quad(0.80 \pm 0.65), \mathrm{P}<0.001$. Consumption of ropivacaine was comparable in both the groups (33.75 \pm $12.16 \mathrm{mg}$ in group R1 and $31.50 \pm 6.62 \mathrm{mg}$ in group R2 P > $0.05)$, but consumption of fentanyl was significantly more in group R1 (54.00 \pm 19.45$)$ as compared to group R2 (31.50 \pm $6.62), \mathrm{P}<0.001$. There were no significant changes in hemodynamics, nor adverse effects related to neonatal or maternal outcomes in both groups.

We found that there was non- significant difference in MAP, MHR and FHR in group I and II at baseline and lowest value (P> 0.05). Chora et al, ${ }^{[9]}$ observed that ropivacaine $0.1 \%$ and bupivacaine $0.1 \%$, with fentanyl $20 \mu \mathrm{g} / \mathrm{mL}$, produced equivalent analgesia for labour. There were no statistically significant differences in the amount of local anaesthetic used, pain scores, sensory levels, motor blockade, labour duration, mode of delivery, and side effects or patient satisfaction amongst the two local anaesthetics using the intermittent top-up technique.

We found that onset on analgesia in group I was 9.5 minutes and in group II was 19.2 minutes. Duration of analgesia in group I was 74.1 minutes and in group II was 64.5 minutes. Cochrane systematic review opined that epidural analgesia appeared to be effective in reducing pain during labor. However, women who used this form of pain relief were at increased risk of having an instrumental delivery. Epidural analgesia had no statistically significant impact on the risk of cesarean section, maternal satisfaction with pain relief and long-term backache and did not appear to have an immediate 
effect on neonatal status as determined by Apgar scores. However, they also stated that further research would be helpful to evaluate rare but potentially severe adverse effects of epidural analgesia on women in labor and long-term neonatal outcomes. ${ }^{[10]}$

\section{Conclusion}

Authors found that combinations of ropivacaine or bupivacaine with fentanyl achieve equally effective and excellent labour analgesia.

\section{References}

1. Writer WD, Stienstra R, Eddleston JM, Gatt SP, Griffin R, Gutsche BB, et al. Neonatal outcome and mode of delivery after epidural analgesia for labour with ropivacaine and bupivacaine: A prospective metaanalysis. Br J Anaesth 1998;81:713-7

2. Beilin $\mathrm{Y}$, Leibowitz AB, Bernstein HH, Abramovitz SE. Controversies of labor epidural analgesia. Anesth Analg 1999;89:969-78

3. Kannan S, Jamison RN, Datta S. Maternal satisfaction and pain control in women electing natural childbirth. Reg Anesth Pain Med
2001;26:468-72.

4. Pearson JF, Davies P. The effect of continuous lumbar epidural analgesia upon fetal acid-base status during the first stage of labour. $\mathbf{J}$ Obstet Gynaecol Br Commonw 1974;81:971-4.

5. Shnider SM, Abboud TK, Artal R, Henriksen EH, Stefani SJ, Levinson G. Maternal catecholamines decrease during labor after lumbar epidural anesthesia. Am J Obstet Gynecol 1983;147:13-5

6. Bang EC, Shin JH, Lee HS, Kang YI, Cho KS, Kim SY. The onset and duration of $0.2 \%$ ropivacaine with a varying dose of fentanyl in epidural labor analgesia. Anesth Pain Med 2010;5:249-54.

7. Ngan Kee WD, Ng FF, Khaw KS, Lee A, Gin T. Determination and comparison of graded dose-response curves for epidural bupivacaine and ropivacaine for analgesia in laboring nulliparous women. Anesthesiology 2010;113:445-53.

8. Chhetty YK, Naithani U, Gupta S, Bedi V, Agrawal I, Swain L. Epidural labor analgesia: A comparison of ropivacaine $0.125 \%$ versus 0.2\% with fentanyl. J Obstet Anaesth Crit Care 2013;3:16-22.

9. Chora I, Hussain A. Comparison of $0.1 \%$ Ropivacaine-Fentanyl with $0.1 \%$ Bupivacaine-Fentanyl Epidurally for Labour Analgesia. Advances in Anesthesiology. 2014;2014.

10. Comparative Obstetric Mobile Epidural Trial (COMET) Study Group UK. Effect of low-dose mobile versus traditional epidural techniques on mode of delivery: A randomised controlled trial. Lancet 2001;358:1923.

Copyright: (C) the author(s), publisher. Academia Anesthesiologica International is an Official Publication of "Society for Health Care \& Research Development". It is an open-access article distributed under the terms of the Creative Commons Attribution Non-Commercial License, which permits unrestricted non-commercial use, distribution, and reproduction in any medium, provided the original work is properly cited.

How to cite this article: Aron V, Lamba K. A Comparative Analysis of Ropivacaine- Fentanyl vs Bupivacaine-Fentanyl in Labour Analgesia. Acad. Anesthesiol. Int. 2019;4(2):234-36.

DOI: dx.doi.org/10.21276/aan.2019.4.2.53

Source of Support: Nil, Conflict of Interest: None declared. 